\title{
Ultrasonic-assisted preparation of $\alpha$-Tocopherol/casein nanoparticles and application in grape seed oil emulsion
}

\author{
Libin Sun ${ }^{\mathrm{a}}$, Hong Wang ${ }^{\mathrm{b}, \mathrm{c}}$, Xiang $\mathrm{Li}^{\mathrm{b}}$, Sheng Lan ${ }^{\mathrm{b}}$, Junguo Wang ${ }^{\mathrm{a}}$, Dianyu Yu ${ }^{\mathrm{c},}$ \\ ${ }^{\text {a }}$ Key Laboratory of Grain and Oil Processing of Jilin Province, Jilin Business and Technology College, Changchun 130507, China \\ ${ }^{\mathrm{b}}$ School of Grain Science and Technology, Jilin Business and Technology College, Changchun 130507, China \\ c School of Food Science, Northeast Agricultural University, Harbin 150030, China
}

\section{A R T I C L E I N F O}

\section{Keywords:}

$\alpha$-tocopherol

Casein

Nanoparticles

Stability

Antioxidant

Ultrasound

\begin{abstract}
A B S T R A C T
In this work casein (CN) was used as a carrier system for the hydrophobic agent $\alpha$-tocopherol ( $\alpha$-TOC), and an amphiphilic self-assembling micellar nanostructure was formed with ultrasound treatment. The interaction mechanism was detected with UV-Vis spectroscopy, fluorescence spectroscopy, proton spectra, and Fourier transform infrared spectroscopy (FTIR). The stability of the nanoparticles was investigated by using typical processing and storage conditions (thermal, photo, $20 \pm 2{ }^{\circ} \mathrm{C}$ and $4 \pm 2{ }^{\circ} \mathrm{C}$ ). Oil-in-water emulsions containing the self-assembled nanoparticles and grape seed oil were prepared, and the effect of emulsion oxidation stability was studied using the accelerated Rancimat method. The results indicated that the UV-Vis spectra of $\alpha$-TOC/CN nanoparticles complexes were different for ultrasonic treatments performed with different combinations of power $(100,200,300 \mathrm{~W})$ and time $(5,10$, and $15 \mathrm{~min})$. The results of UV-Vis fluorescence spectrum data indicated that the secondary structure of casein changed in the presence of $\alpha$-TOC. The nanoparticles exhibited the chemical shifts of conjugated double bonds. Interactions between $\alpha$-TOC and casein at different molar concentrations resulted in a quenching of the intrinsic fluorescence at $280 \mathrm{~nm}$ and $295 \mathrm{~nm}$. Moreover, by performing FTIR deconvolution analysis and multicomponent peak modeling, the relative quantitative amounts of $\alpha$-helix and $\beta$-sheet protein secondary structures were determined. The self-assembled nanoparticles can improve the stability of $\alpha$-TOC by protecting them against degradation caused by light and oxygen. The antioxidant activity of the nanoparticles was stronger than those of the two free samples. Lipid hydroperoxides remained at a low level throughout the course of the study in emulsions containing $200 \mathrm{mg} \alpha$-TOC/ $\mathrm{kg}$ oil with the nanoparticles. The presence of 100 and $200 \mathrm{mg} \alpha$-TOC/kg oil led to a 78.54 and $63.54 \mu \mathrm{mol} / \mathrm{L}$ inhibition of TBARS formation with the nanoparticles, respectively, vs the free samples containing control after 180 mins.
\end{abstract}

\section{Introduction}

Vitamin $\mathrm{E}$ is a fat-soluble vitamin composed of eight different forms of tocopherols ( $\alpha, \beta, \gamma$, and $\delta$ ) and tocotrienols ( $\alpha, \beta, \gamma$, and $\delta$ ) [19]. Vitamin E compounds are known to inhibit lipid oxidation in foods, and the most biologically active of these compounds is $\alpha$-TOC $[31,33]$. Therefore, it has been used as a food additive [6]. $\alpha$-TOC is known to protect polyunsaturated lipids by binding and trapping free radicals and by quenching singlet molecular oxygen [24].

The lipophilic compound $\alpha$-TOC is poorly soluble in water and biologically unstable against factors such as light and oxygen. This limits its storage and applications in the pharmaceutical, food, and cosmetic industries $[20,30]$. The existing delivery systems have been designed to improve the performance of $\alpha$-TOC with the advantages of low dose frequency and superior bioactivity and stability, for example, in microencapsulation [41], liposomes [29] and as nanoparticles [13]. Multiple methods for encapsulating $\alpha$-TOC in polymeric nanoparticles have been reported, but studies and applications related to the preparation of $\alpha$-tocopherol/casein nanoparticles by using ultrasound have not been reported thus far. Moreover, details pertaining to the strength and mechanism of the interaction between casein and $\alpha$-TOC by ultrasonic treament have not been revealed yet. Thus, the objective of the present study is to determine the ultrasound conditions required to produce more stable $\alpha$-tocopherol/casein nanoparticles.

Casein is an amphiphilic self-assembling protein, and it offers certain advantages as a natural vehicle for bioactive compounds [3]. The

\footnotetext{
* Corresponding author.

E-mail address: dyyu2000@126.com (D. Yu).
} 
structural and physicochemical properties of casein, have been described, such as the binding of ions and small molecules and excellent emulsification and self-assembly properties $[8,26,32,42]$. Furthermore, casein reportedly interacts with bioactive compounds, such as blueberry anthocyanins [45] and vitamin A [32]. These reports explore the effects of carriers on bioactive compounds under various processing conditions and their interaction mechanism. The protective effects of casein on the stability and antioxidant capacity of $\alpha$-TOC and their interaction mechanism are reported in this study. Fourier deconvolution analysis and Gaussian curve fitting are employed to provide detailed information on the structure of casein after ultrasonic treatment.

In contrast to previous reports about nanoparticles, the present study attempts to evaluate the influences of different ultrasound powers and ultrasound times on the particle size, polydispersity index, and protein structure of the encapsulated nanoparticles loaded with $\alpha$-TOC. The protective effects of casein on the stability and antioxidant capacity of $\alpha$-TOC are examined. The strength and mechanism of interation between casein and $\alpha$-TOC are elucidated using different spectroscopic methods and proton spectra. Moreover, the antioxidant ability is employed to produce a grape seed oil emulsion by using the lipid hydroperoxides $(\mathrm{LOOH})$ and thiobarbituric acid reactive substances (TBARS) assays.

\section{Materials and methods}

\subsection{Materials}

Casein sodium salt, $\alpha$-TOC (purity of 96\%), and 1, 1, 3, 3-tetraethoxypropane were purchased from Sigma-Aldrich Chemical Co. (St. Louis, MO, USA). Cumene hydroperoxide was purchased from Sigma-Aldrich Chemical Co. (St. Louis, MO, USA). All other chemicals of analytical grade were purchased from Sinopharm Chemical Reagent Co. Ltd. (Shanghai, China). Ultrapure water was utilized throughout.

\subsection{Methods}

\subsubsection{Sample preparation}

Self-assembled casein nanoparticles containing $\alpha$-TOC were prepared as described by Semo et al. [7]. The $\alpha$-TOC solution was prepared as follows: $0.01,0.007$, and $0.005 \mathrm{~g}$ of $\alpha$-TOC were dissolved separately in $10 \mathrm{~mL}$ of anhydrous ethanol, and the resulting solutions were oscillated for $2 \mathrm{~min}$. After the complete dissolution of $\alpha$-TOC, the solutions were stored in a refrigerator $\left(4 \pm 2{ }^{\circ} \mathrm{C}\right)$. Casein was dissolved in distilled water at a concentration of $2 \mathrm{mg} / \mathrm{mL}$. The $\mathrm{pH}$ was adjusted to about 10 by using $0.1 \mathrm{~mol} / \mathrm{L} \mathrm{NaOH}$. This system was stirred at room temperature for $3 \mathrm{~h}$ and then stored in a refrigerator $\left(4 \pm 2{ }^{\circ} \mathrm{C}\right)$ for $8 \mathrm{~h}$. Thereafter, the system $\mathrm{pH}$ was adjusted to about 6.8 by using $0.1 \mathrm{~mol} / \mathrm{L} \mathrm{HCl}$. Then, $\alpha$-TOC was added to the system in different mass ratios (Table 1 ), and the resulting samples were treated in an ultrasonic cell crusher (on $2 \mathrm{~s}$, off 3

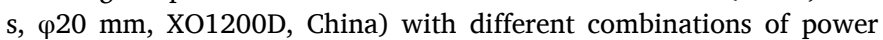
$(100,200,300 \mathrm{~W})$ and treatment duration $(5,10$, and $15 \mathrm{~min})$. Approximately $4 \mathrm{~mL}$ of $1 \mathrm{~mol} / \mathrm{L}$ tripotassium citrate, $24 \mathrm{~mL}$ of $0.2 \mathrm{~mol} / \mathrm{L}$ $\mathrm{K}_{2} \mathrm{HPO}_{4}$, and $20 \mathrm{~mL}$ of $0.2 \mathrm{~mol} / \mathrm{L} \mathrm{CaCl}_{2}$ were added. Thereafter, four

Table 1

Orthogonal experimental design.

\begin{tabular}{lllll}
\hline Column & 1 & 2 & 3 & 4 \\
\hline Factor & Ultrasonic time/min & Ultrasonic power/W & Mass ratio & Control \\
1 & 5 & 100 & $1: 200$ & 1 \\
2 & 5 & 200 & $1: 300$ & 2 \\
3 & 5 & 300 & $1: 400$ & 3 \\
4 & 10 & 100 & $1: 300$ & 3 \\
5 & 10 & 200 & $1: 400$ & 1 \\
6 & 10 & 300 & $1: 200$ & 2 \\
7 & 15 & 100 & $1: 400$ & 2 \\
8 & 15 & 200 & $1: 200$ & 3 \\
9 & 15 & 300 & $1: 300$ & 1 \\
\hline
\end{tabular}

consecutive additions of $2.5 \mathrm{~mL}$ of $0.2 \mathrm{~mol} / \mathrm{L} \mathrm{K}_{2} \mathrm{HPO}_{4}$ and $5 \mathrm{~mL}$ of 0.2 $\mathrm{mol} / \mathrm{L} \mathrm{CaCl} 2$ were performed at 15 -min intervals. During this process, the samples were stirred with a magnetic stirrer, sample temperature was maintained at $37{ }^{\circ} \mathrm{C}$, and sample $\mathrm{pH}$ was adjusted between 6.8 and 7.0 by using either $0.1 \mathrm{~mol} / \mathrm{L} \mathrm{HCl}$ or $0.1 \mathrm{~mol} / \mathrm{L} \mathrm{NaOH}$. The final dispersions were stirred at $350 \mathrm{r} / \mathrm{min}$ for $1 \mathrm{~h}$. The samples were then treated for $20 \mathrm{~s}$ at $74{ }^{\circ} \mathrm{C}$ in a water bath. The control sample was prepared by following the same procedure.

\subsubsection{Preparation of grape seed oil emulsion}

A grape seed oil emulsion was prepared following the method described by Shao \& Tang [44]. Oil-in-water emulsions containing grape seed oil $(30 \%, w / w)$ in the oil phase were produced using a high-speed blender (Fluko, Shanghai, China) operated at 10,000 rpm for $3 \mathrm{~min}$. The oil droplet size was further reduced using a high-pressure homogenizer (Ah-Basic, ATS) operated at $50 \mathrm{MPa}$. Nanoparticles prepared with a mass ratio of 1:200 were added to the emulsions. The ultrasound treatment power was $300 \mathrm{~W}$, and the duration was $5 \mathrm{~min}$, respectively. The net $\alpha$-TOC contents were $100 \mathrm{mg} / \mathrm{kg}$ and $200 \mathrm{mg} / \mathrm{kg}$, respectively. The mixtures were then homogenized twice at $50 \mathrm{MPa}$ by using a highpressure homogenizer (Ah-Basic, ATS) to improve nanoparticle distribution in the interfacial regions.

Approximately $3 \mathrm{~mL}$ of the emulsions were placed in a professional rancimat (Metrohm, 892, Swiss) and removed at 30-min intervals between 0 and $3 \mathrm{~h}$. Accelerated oxidation conditions were employed. The heater temperature and gas flow rate were set to $60{ }^{\circ} \mathrm{C}$ and $20 \mathrm{~L} / \mathrm{h}$, respectively. The emulsions were prepared in duplicate for the $\mathrm{LOOH}$ and TBARS assays.

\subsection{Experimental design}

An orthogonal rotation combination test design comprising three levels and four factors, namely ultrasonic treatment power, ultrasonic treatment time, mass ratio, and control, was used to optimize the model and reaction conditions (Table 1). Encapsulation efficiency was set as the index of this ultrasound process.

Encapsulation efficiency was determined following a modified version of a procedure described in the literature [19]. Encapsulation efficiency was defined as the difference between the total $\alpha$-TOC content used during preparation and the free $\alpha$-TOC content obtained after separation from the medium. Briefly, the suspensions were accurately injected into a centrifugal ultrafiltration device. Filtrates were extracted from the suspensions by means of centrifugation at $4000 \mathrm{rpm}$ for $30 \mathrm{~min}$. Hexane was added to the $\alpha$-TOC extracted from the filtrate and the resulting mixture was subjected to vortexing. The free $\alpha$-TOC concentration was assayed using a UV-Vis spectrophotometer (Agilent, Cary 60, Malaysia) at $297 \mathrm{~nm}$. The encapsulation efficiency (EE, \%) was calculated using equation (1):

$E E(\%)=\frac{W_{t}-W_{f}}{W_{t}} \times 100$

where $W_{t}$ is the total amount of $\alpha$-TOC used during the preparation, and $W_{f}$ is the amount of free $\alpha$-TOC in the filtrate.

\subsection{UV-Vis spectroscopy and calibration curve}

The self-assembled casein nanoparticles were dissolved in phosphate buffer solution (PBS, $\mathrm{pH}=7.0$ ) with the final concentration of $0.15 \mathrm{mg}$ / $\mathrm{mL}$. UV-Vis spectra of the solution were recorded with a UV-Vis spectrophotometer (Agilent, Cary 60, Malaysia) scanning from 190 to 400 $\mathrm{nm}$ at room temperature. The scan resolution was $0.5 \mathrm{~nm}$, scanning step was $1 \mathrm{~nm}$, and scanning rate was $50 \mathrm{~nm} / \mathrm{min}$. PBS was used as a blank control [24,27].

A absorbance vs concentration calibration curve was plotted for different concentrations of $\alpha$-TOC dissolved in hexane. Initially, $200 \mathrm{mg}$ of $\alpha$-TOC was accurately weighed, and the volume was eventually 
increased to $100 \mathrm{~mL}$ by adding hexane. Then, $1 \mathrm{~mL}$ of the solution was placed in a 10-mL volumetric flask, and the volume of this solution was eventually increased to $10 \mathrm{~mL}$ by adding hexane; the resulting solution was called the working solution. Approximately $0.5,1.0,1.5,2.0$, and $2.5 \mathrm{~mL}$ of the working solution were accurately weighed and eventually diluted to $10 \mathrm{~mL}$ by using hexane. The absorbance of the diluted samples was assayed using a UV-Vis spectrophotometer (Agilent, Cary 60, Malaysia) at $297 \mathrm{~nm}$. A hexane sample was used as the blank control. The standard curve was plotted with the mass concentration of $\alpha$-TOC as the abscissa and its absorbance as the ordinate. The following onedimensional linear regression equation was obtained: $\mathrm{y}=15.737 \mathrm{x}+$ $0.0252, \mathrm{R}^{2}=0.9963$.

\subsection{Proton spectra}

Nuclear magnetic resonance (NMR) spectra were recoded using a Bruker Avance III HD instrument. ${ }^{1} \mathrm{H}$ NMR spectra were obtained with a spectral width of $500 \mathrm{MHz}$, acquisition time of $3.9 \mathrm{~s}$, delay of $2 \mathrm{~s}$, and pulse angle of $45^{\circ}$. The proton spectrum analysis was performed with a total of 16 scans.

\subsection{Size determination}

The particle size and PDI of the $\alpha$-TOC/CN nanoparticles were measured after the resuspension of lyophilized nanoparticles by using the modified method reported by Zigoneanu et al. [13]. The particle size and PDI of both casein and $\alpha$-TOC/CN nanoparticles were determined with dynamic light scattering (Nano ZS, Malvern, UK) by using a $\mathrm{He} / \mathrm{Ne}$ laser $(\lambda=632.8 \mathrm{~nm})$. Particle size analysis of the emulsion droplets was performed at $25^{\circ} \mathrm{C}$ by following a previously described procedure [39]. All measurements were repeated thrice.

\subsection{Fluorescence spectroscopy}

The molar concentration ratio of $\alpha$-TOC to casein was set variously to $3: 1,4: 1$, and 5:1. Fluorescence spectroscopy was performed using a spectrofluorometer (Gangdong, F-280, China) scanning from 250 to 380 $\mathrm{nm}$ at the excitation wavelengths of $280 \mathrm{~nm}$ and $295 \mathrm{~nm}$. The excitation and emission bandwidth was $10 \mathrm{~nm}$, and the scan speed was $60 \mathrm{~nm} / \mathrm{min}$; PBS was used as the blank control $[2,47]$.

\subsection{Fourier transform infrared spectroscopy}

Fourier transform infrared (FTIR) analysis was performed using a Fourier transform infrared spectrometer (Shimadzu, IR Affinity-1, Japan) scanning from 4,000 to $400 \mathrm{~cm}^{-1}$ at room temperature. $\mathrm{KBr}$ was pressed into plates and solution samples were dripped onto these plates for measurement. The analysis was performed with a total of 32 scans at the resolution of $4 \mathrm{~cm}^{-1}$.

\subsection{Stability testing}

To investigate nanoparticle stability, stability tests were conducted under modified versions of four conditions described in the literature $[19,29,45]$. A photo stability test was conducted by exposing the samples to an illumination intensity of $15 \mathrm{~W}$ for $180 \mathrm{~min}$. A thermal treatment stability test was conducted by heating the samples in an air dry oven at $50{ }^{\circ} \mathrm{C}$ for $6 \mathrm{~h}$. Storage stability tests were conducted for $6 \mathrm{~d}$ at room temperature $\left(20 \pm 2{ }^{\circ} \mathrm{C}\right)$ and in a refrigerator $\left(4 \pm 2{ }^{\circ} \mathrm{C}\right)$. The stability of the self-assembled casein nanoparticles was compared with that of the free $\alpha$-TOC.

The retention rate was presented as the remaining absorbance with time of exposure. The nanoparticle samples treated under the four aforementioned conditions were mixed with anhydrous ethanol in equal volume with stirring, and $200 \mu \mathrm{L}$ of $1 \mathrm{~mol} / \mathrm{L} \mathrm{NaOH}$ was added into the mixtures. $\alpha$-TOC was extracted from the emulsions by using hexane until the water phase was colorless and transparent, and the free $\alpha$-TOC concentration was assayed using a UV-Vis spectrophotometer (Agilent, Cary 60, Malaysia) at $297 \mathrm{~nm}$.

\subsection{Antioxidant activity testing}

LOOH was determined according to a previously described procedure [37]. A sample $(0.3 \mathrm{~mL})$ was mixed in a glass tube with $1.5 \mathrm{~mL}$ isooctyl alcohol-isopropanol $(3: 1, \mathrm{v} / \mathrm{v})$ on a vortex mixer for $10 \mathrm{~s}$ and centrifuged at $4,000 \mathrm{rpm}$ for $10 \mathrm{~min}$ to separate the phases. A $200-\mu \mathrm{l}$ sample of the resulting supernatant (organic phase) was mixed thoroughly with $2.8 \mathrm{~mL}$ of methanol-butyl alcohol (2:1, v/v). Ammonium thiocyanate solution $(50 \mu \mathrm{L}, 3.94 \mathrm{~mol} / \mathrm{L})$ was added to the resulting mixture. Then, $50 \mu \mathrm{L}$ of iron (II) solution was added, and the resulting mixture was mixed using a vortex mixer for $5 \mathrm{~s}$. After incubation for 20 min at room temperature with appropriate stirring, the absorbance of the sample was determined at $510 \mathrm{~nm}$ against a blank that contained all of the reagents except for the sample by using a UV-Vis spectrophotometer (Agilent, Cary 60, Malaysia). LOOH concentrations were determined from a standard curve prepared using cumene hydroperoxide.

The secondary oxidation products were monitored with the thiobarbituric acid reactive substances (TBARS) method by following a procedure described elsewhere $[37,48]$. Approximately $2 \mathrm{~mL}$ of each sample was mixed with $4 \mathrm{~mL}$ of TBA reagent containing $15 \% \mathrm{w} / \mathrm{v}$ trichloloracetic acid and $0.375 \% \mathrm{w} / \mathrm{v}$ thiobarbituric acid in $0.25 \mathrm{~mol} / \mathrm{L}$ $\mathrm{HCl}$ in screw-capped tubes and placed in a boiling water bath for $15 \mathrm{~min}$. The samples were then cooled to room temperature and centrifuged at $1,600 \mathrm{~g}$ for $20 \mathrm{~min}$. The absorbance of the supernatant was measured at $532 \mathrm{~nm}$ by using a UV-Vis spectrophotometer (Agilent, Cary 60, Malaysia). The TBARS concentrations were determined from a standard curve prepared using 1,1,3,3-tetraethoxypropane.

\subsection{Statistical analysis}

The experimental data were statistically analyzed and expressed using SPSS20.0 (IBM Corp., Armonk, NY, USA). All diagrams were plotted using Origin 8.1 software (Microcal, USA). The significance correlations were defined as $(\mathrm{p}<0.05)$ and $(\mathrm{p}<0.01)$.

\section{Results and discussion}

\subsection{UV-Vis spectra of casein after binding with $\alpha$-TOC}

The interaction of small molecules with protein was investigated by means of UV-Vis spectroscopy to confirm the structural changes that occurred in the protein during ultrasonic treatment. Changes in the peak wavelength and absorption spectral intensity of the small molecules with protein represent the strength and mechanism of the interaction.

The UV-Vis spectra of $\alpha$-TOC/CN nanoparticles exhibited significant changes (Fig. 1). Two distinct characteristic absorption peaks were observed in the wavelength ranges of 195.5-212 nm and 275.5-285.5 $\mathrm{nm}$. The former wavelength range was mainly characterized by changes in peptide bonds, that is, the $\alpha$-helix structure of protein, while the latter wavelength was mainly characterized by the absorption peaks of chromogenic groups such as tryptophan and tyrosine [34]. The absorbance intensities of $\alpha$-TOC/CN nanoparticles was different during intensity measurements in the case of all of the ultrasonic treatments investigated herein (Fig. 1). A possible reason is that the hydrophobic groups in denatured proteins were exposed upon ultrasonic treatment [11,35], resulting in increased fluorescence intensity. Fig. 1 shows that the maximum absorption wavelength (195.5-212 nm) of the system increased with the addition of $\alpha$-TOC, which led to the formation of $\alpha$-TOC/CN. These results agreed with those of Tang et al. [22], who reported that the absorption wavelength of C3G-BSA increased with the addition of C3G. The secondary structure of casein was affected by the 


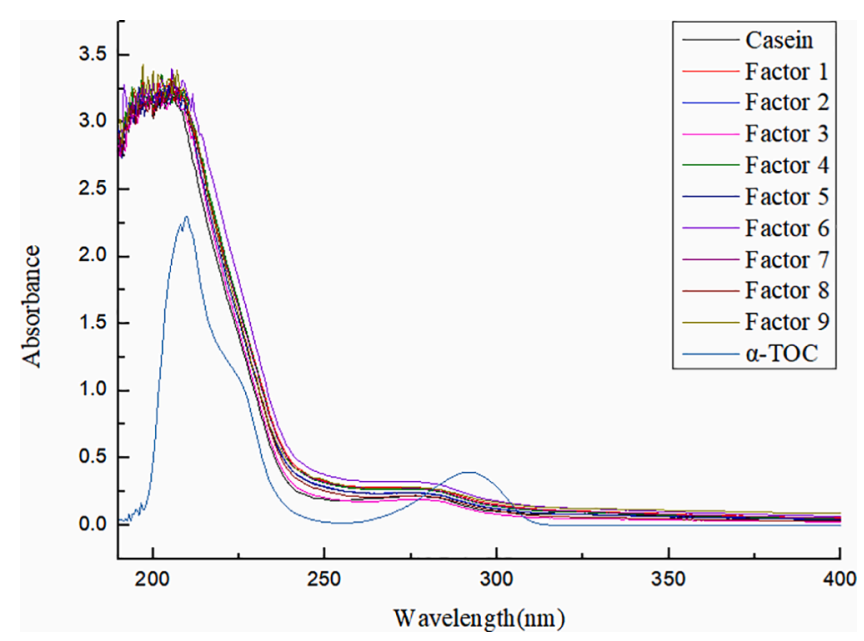

Fig. 1. The changes of UV-Vis spectra under orthogonal experimental design.

newly formed compound [22]. As reported by Hu et al. [11] and Zhang et al. [35], the functional properties of protein can be modified with ultrasound treatment, which induces several secondary structural changes as well. These effects of ultrasound are consistent with the results reported in the literature, wherein the mechanism of ultrasound was confirmed $[10,11,16,35]$.

The untreated samples formed more elastic and compact dispersions, while the ultrasonic-treated samples formed more viscous and loosened dispersions. This is because as the ultrasonic treatment time and power increase, as a protein denatured, more hydrophobic groups are exposed due to the instantaneous extreme temperatures and pressures generated by ultrasound $[14,35]$. Moreover, the results indicated that the optimum orthogonal array design analysis conditions were as follows: Ultrasonic power $=300 \mathrm{~W}$, ultrasonic treatment time $=5 \mathrm{~min}$, and mass ratio $=$ 1:200. The nanoparticles prepared using the optimized conditions exhibited an encapsulation efficiency of $97.29 \pm 5.2 \%$. These results suggest that there is a balance between the aggregation and exposure of hydrophobic groups [4], resulting in the formation of self-assembled nanoparticles with a hydrophobic core, which could be ideal nanoscale carriers for lipophilic drugs [3,23].

\subsection{Proton spectra}

The two purified products ( $\alpha$-TOC and casein) and $\alpha$-TOC/CN nanoparticles were characterized with ${ }^{1} \mathrm{H}$ NMR. The chemical shifts were read and are presented in Fig. 2. Compared to the free samples, the nanoparticles exhibit the chemical shifts of conjugated double bonds, as can be observed from their spectrum. A combined analysis of UV, Fluorescence spectra and NMR data confirmed the binding of casein to $\alpha$-TOC.

\subsection{Size determination}

As summarized in Table 2, the average diameters of the casein particles were $198.40 \pm 0.56 \mathrm{~nm}$ and $170.93 \pm 1.86 \mathrm{~nm}$ with and without ultrasound treatment, respectively. The average PDI of the $\alpha$-TOC/CN nanoparticles (under optimum conditions) was $0.24 \pm 0.02$, which was slightly smaller. Madadlou et al. [5] observed similar results for casein micelles, which indicates that the homogeneity of the particles increased owing to sonication. Nanoparticles were added into the formed emulsions post-treatment by using a high-pressure homogenizer. The emulsions produced with the net $\alpha$-TOC content of $100 \mathrm{mg} / \mathrm{kg}$ had a mean droplet size of $296.07 \pm 15.14 \mathrm{~nm}$, whereas the emulsions produced with the net $\alpha$-TOC content of $200 \mathrm{mg} / \mathrm{kg}$ had a smaller mean droplet size of $251.43 \pm 16.97 \mathrm{~nm}$. A possible reason was that the mean droplet size decreased as the amount of casein added increased [39].

\subsection{Fluorescence spectra of casein after binding with $\alpha$-TOC}

Information about the binding properties of small molecules to protein, such as the binding mechanism, binding model, binding constant, and binding sites, can be gleaned from their fluorescence spectra [46]. The fluorescence spectra of nanoparticles recorded at $280 \mathrm{~nm}$ and $295 \mathrm{~nm}$ in the presence of different molar concentrations of $\alpha$-TOC are shown in Fig. 3.

The fluorescence intensity of a protein can mainly be ascribed to the Trp, Tyr, and Phe residues $[9,23]$. According to Fig. 3, the fluorescence intensity of casein decreases regularly with a gradual increase in the

Table 2

Change of particle size and PDI of casein solution as a result of sonication.

\begin{tabular}{lll}
\hline & $\begin{array}{l}\text { particle size } \\
(\mathrm{nm})\end{array}$ & PDI \\
\hline Casein (without ultrasound treatment) & $198.40 \pm 0.56$ & $0.40 \pm$ \\
& & 0.01 \\
& $170.93 \pm 1.86$ & $0.24 \pm$ \\
$\alpha$-Tocopherol/casein nanoparticles (with & & 0.02 \\
ultrasound treatment) & & \\
\hline
\end{tabular}

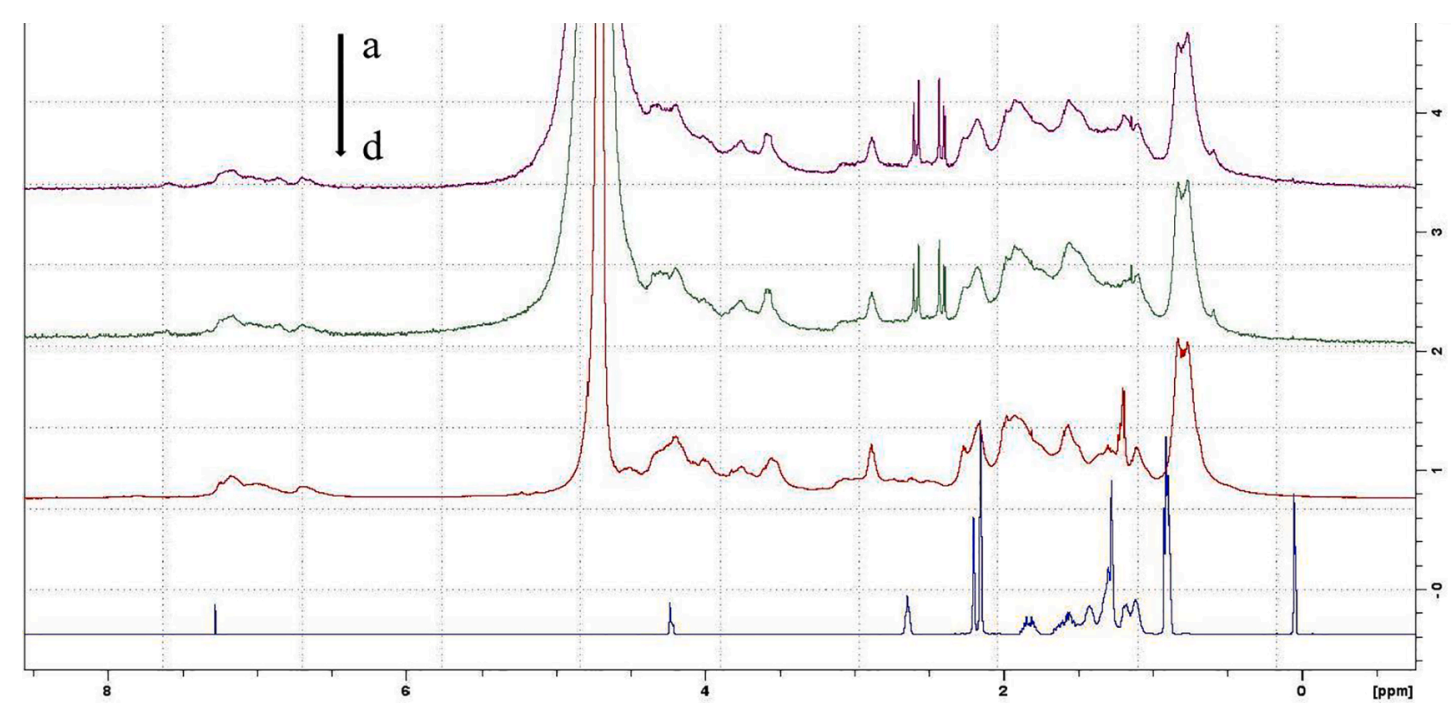

Fig. 2. ${ }^{1} \mathrm{H}$ NMR spectrum of samples. (a) $\alpha$-TOC/CN nanoparticles without ultrasound, (b) $\alpha$-TOC/CN nanoparticles with ultrasound, (c) casein, (d) $\alpha$-TOC. 

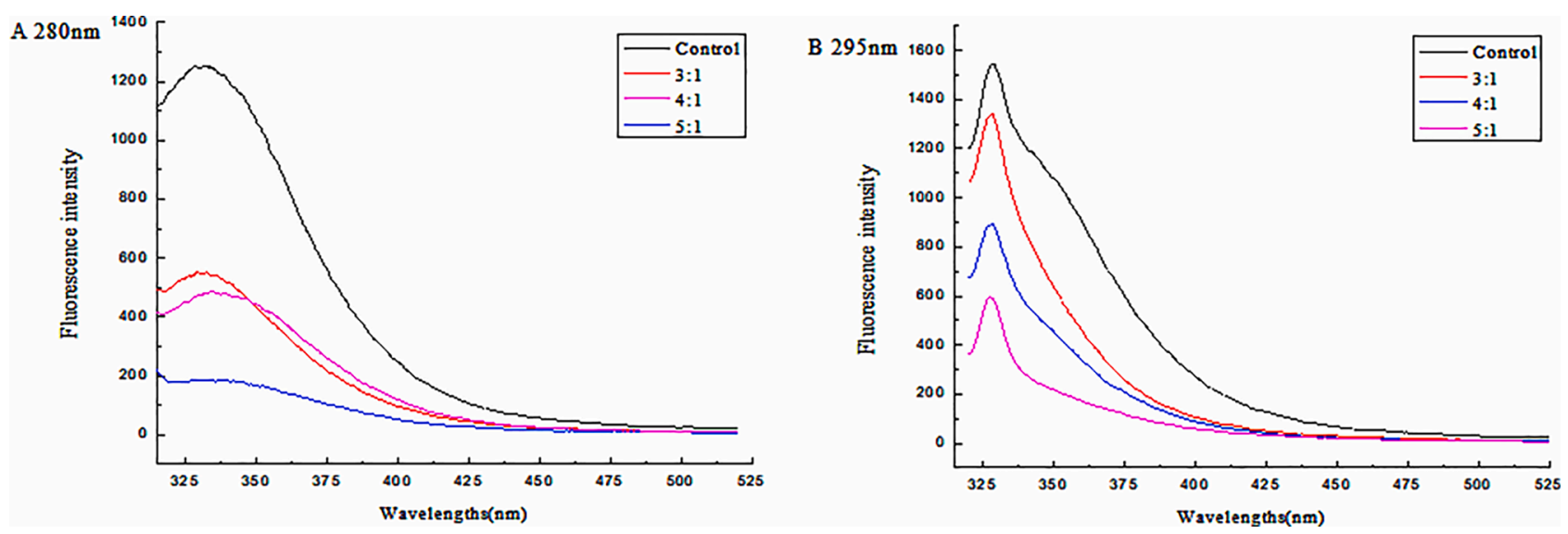

Fig. 3. The changes of fluorescence spectra under different molar concentration ratio.

$\alpha$-TOC concentration, indicating that the interaction between casein and $\alpha$-TOC occurred, and $\alpha$-TOC/CN complexes were formed. Liang, Tremblay-Hebert, \& Subirade [21] reported that binding of $\alpha$-tocopherol to $\beta$-lg which reduced the turbidity and improved the solubility of fatsoluble vitamins and that the fluorescence intensity decreased with the addition of $\alpha$-tocopherol. In addition, when the excitation wavelength was $280 \mathrm{~nm}$ (Fig. 3A), the maximum emission wavelength of casein exhibited a red shift, which indicated that the chromophore of casein was placed in a more hydrophobic environment upon the addition of $\alpha$-TOC. Changes to the protein structure were more remarkable, and the structure was more relaxed and loose $[1,25]$. When the excitation wavelength was $295 \mathrm{~nm}$ (Fig. $3 \mathrm{~B}$ ), the maximum emission wavelength of casein did not present a red or blue shift. According to the literature, the major amino acids involved in the interaction of protein with hydrophobic compounds are Tyr, Phe, Trp, Leu, and Val. Moreover, reassembly enhanced the bond between $\alpha$-TOC and hydrophobic protein groups. These structural and physicochemical properties of proteins facilitate their functionality as carriers if different bioactive compounds and micronutrients [3,43]. Esmaili et al. [23] encapsulated thehydrophobic curcumin with amphiphilic self-assembling protein, and as a result, the solubility, bioavailability, and antioxidant activity of curcumin increased. For this reason, the present study worked to improve the binding ability of this modified protein because hydrophobic interactions are major forces that occur during the interaction of $\alpha$-TOC with protein.

\subsection{FTIR characterization of casein after binding with $\alpha$-TOC}

The FTIR spectra of proteins exhibit a number of amide bands that represent different vibrations of peptide moieties, such as the bands corresponding to amide I (1,600-1,700 $\mathrm{cm}^{-1}$, mainly $\mathrm{C}=\mathrm{O}$ stretch), amide II $\left(1,600-1,500 \mathrm{~cm}^{-1}\right.$, C-N stretch coupled with $\mathrm{N}-\mathrm{H}$ bending mode), amide III $\left(1,330-1,220 \mathrm{~cm}^{-1}, \mathrm{C}-\mathrm{N}\right.$ stretching vibration and $\mathrm{N}-\mathrm{H}$ deformation of peptide group) $[18,36,40]$.

The FTIR spectra of the $\alpha$-TOC/CN nanoparticles is shown in Fig. 4. The peak positions of amide I bands are shifted in the infrared spectrum of casein after the interaction of casein with $\alpha$-TOC. The changes to these peak positions and peak shapes demonstrated that the secondary structure of casein was altered, indicating the occurrence of an interaction between $\alpha$-TOC and casein.

When both criteria I and II were fulfilled and the integral areas of the amide I band were normalized, it was possible to use the relative areas of the deconvoluted amide I bands to directly determine the relative amounts of different types of secondary structures. As shown in Fig. 5, Fourier deconvolution analysis and Gaussian curve fitting were performed to obtain detailed information about the protein structure.

Before estimation of the percentage content of each secondary

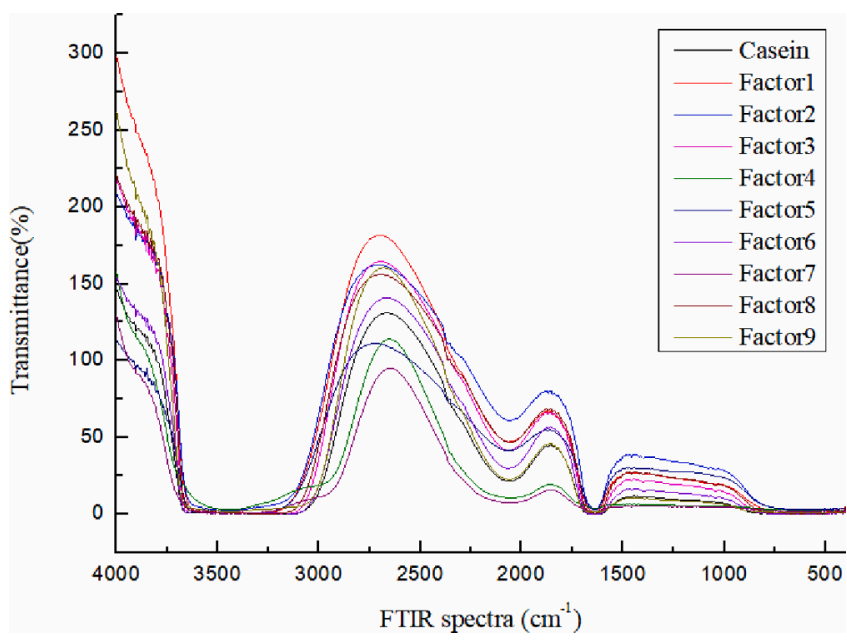

Fig. 4. The changes of FTIR spectra under orthogonal experimental design.

structure, the component bands should be assigned. The band 1,650-1 $658 \mathrm{~cm}^{-1}$ is typically assigned to the $\alpha$-helix structure. In case of the $\beta$-sheet structure, the amide I band is generally in the range of $1,610-1,640 \mathrm{~cm}^{-1}$. The peaks of the random coil and $\beta$-turn structures can be found within the ranges of $1,640-1,650 \mathrm{~cm}^{-1}$ and $1,660-1,700$ $\left.\mathrm{cm}^{-1}[15,17]\right)$. A quantitative analysis of each secondary structure was performed considering the integrated areas of the component bands in amide $\mathrm{I}$, as summarized in Table 3.

The ratio of $\alpha$-helix to $\beta$-sheet structures in casein was 0.62 ; in case of the $\alpha$-TOC/CN nanoparticles, the ratio decreased to $0.246-0.494$. These results indicated that the flexibility of the internal structure of the protein increased.

\subsection{Stability of $\alpha-T O C / C N$ nanoparticles}

According to Table 4, the storage stabilities of the nanoparticles investigated under four conditions are significantly different.

As the storage time increased from 1 to $6 \mathrm{~h}$, the retention rate of the self-assembled nanoparticles decreased by $10.39 \%$ and $56.43 \%$. Moreover, the retention rate of free $\alpha$-TOC decreased by 1.21-1.26 times from $13.06 \%$ to $68.39 \%$ as the storage time in the refrigerator $\left(4{ }^{\circ} \mathrm{C}\right)$ increased.

The retention rates of the self-assembled casein nanoparticles and the free $\alpha$-TOC were $42.65 \%$ and $19.05 \%$ (6d) at room temperature, respectively. However, the storage stability exhibited the similar trends at room temperature and in a refrigerator $\left(4 \pm 2{ }^{\circ} \mathrm{C}\right)$, and the difference between the two stability values was not significant. However, 
L. Sun et al.

Ultrasonics Sonochemistry 80 (2021) 105810
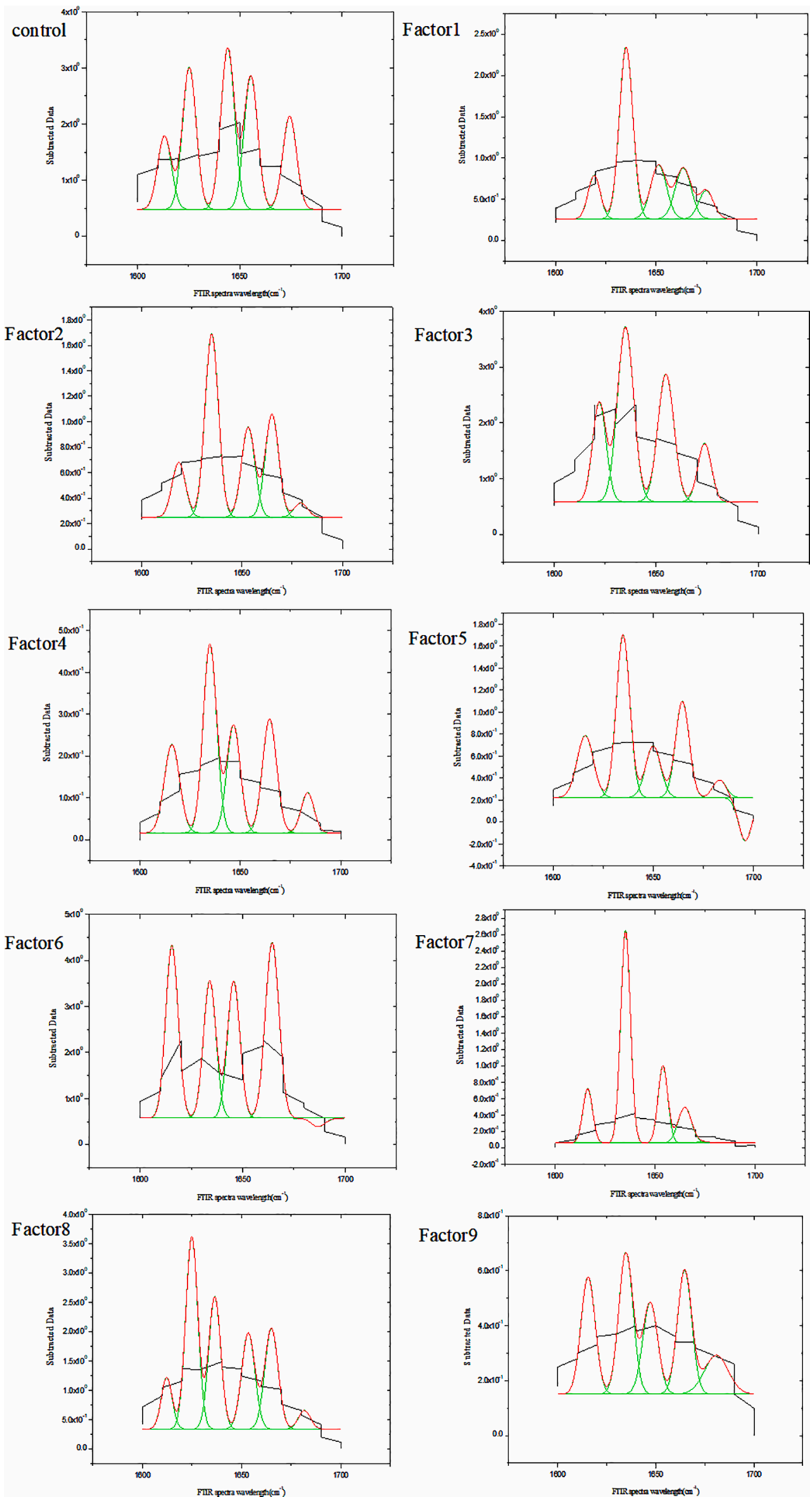

Fig. 5. The Fourier deconvolution analysis and Gaussian curve fitting.

6 
Table 3

Changes of secondary structure content.

\begin{tabular}{|c|c|c|c|c|c|c|c|c|c|c|}
\hline Test & 0 & 1 & 2 & 3 & 4 & 5 & 6 & 7 & 8 & 9 \\
\hline Ratio of $\alpha$-helix to $\beta$-sheet & 0.62 & 0.301 & 0.378 & 0.494 & 0.374 & 0.246 & 0.442 & 0.29 & 0.285 & 0.378 \\
\hline
\end{tabular}

Table 4

Stability testing of nanoparticles with defferent treatments (presented as the remaining absorbance in each fraction with time of exposure)

\begin{tabular}{|c|c|c|c|c|c|c|c|c|c|c|}
\hline \multirow{2}{*}{$\begin{array}{l}\text { Treatment } \\
\text { time }\end{array}$} & \multicolumn{2}{|c|}{ In a refrigerator $\left(4^{\circ} \mathrm{C}\right)$} & \multicolumn{2}{|c|}{ At room temperature } & \multirow{2}{*}{$\begin{array}{l}\text { Exposure } \\
\text { time }\end{array}$} & \multicolumn{2}{|l|}{$\underline{\text { UV light }}$} & \multirow{2}{*}{$\begin{array}{l}\text { Treatment } \\
\text { time }\end{array}$} & \multicolumn{2}{|c|}{ In a air dry oven $\left(50^{\circ} \mathrm{C}\right)$} \\
\hline & Nanoparticles & $\begin{array}{l}\alpha \text {-TOC } \\
\text { (control) }\end{array}$ & Nanoparticles & $\begin{array}{l}\alpha \text {-TOC } \\
\text { (control) }\end{array}$ & & Nanoparticles & $\begin{array}{l}\alpha \text {-TOC } \\
\text { (control) }\end{array}$ & & Nanoparticles & $\begin{array}{l}\alpha \text {-TOC } \\
\text { (control) }\end{array}$ \\
\hline od & $\begin{array}{l}0.914 \pm 0.009 \\
\mathrm{aA}\end{array}$ & $\begin{array}{l}0.528 \pm \\
0.020 \mathrm{aD}\end{array}$ & $\begin{array}{l}0.910 \pm 0.005 \\
\mathrm{aA}\end{array}$ & $\begin{array}{l}0.528 \pm \\
0.020 \mathrm{aD}\end{array}$ & $0 \mathrm{~min}$ & $\begin{array}{l}0.863 \pm 0.009 \\
\mathrm{aB}\end{array}$ & $\begin{array}{l}0.795 \pm \\
0.005 \mathrm{aC}\end{array}$ & $0 \mathrm{~h}$ & $\begin{array}{l}0.864 \pm 0.008 \\
\mathrm{aB}\end{array}$ & $\begin{array}{l}0.773 \pm \\
0.018 \mathrm{aC}\end{array}$ \\
\hline $1 d$ & $\begin{array}{l}0.819 \pm 0.030 \\
\text { bB }\end{array}$ & $\begin{array}{l}0.45933 \pm \\
0.011 \mathrm{bE}\end{array}$ & $\begin{array}{l}0.866 \pm 0.009 \\
\text { bA }\end{array}$ & $\begin{array}{l}0.433 \pm \\
0.029 \mathrm{bE}\end{array}$ & $30 \mathrm{~min}$ & $\begin{array}{l}0.819 \pm 0.011 \\
\text { abB }\end{array}$ & $\begin{array}{l}0.732 \pm \\
0.015 \mathrm{aC}\end{array}$ & $1 \mathrm{~h}$ & $\begin{array}{l}0.732 \pm 0.027 \\
\mathrm{bC}\end{array}$ & $\begin{array}{l}0.578 \pm \\
0.035 \mathrm{bD}\end{array}$ \\
\hline $2 d$ & $\begin{array}{l}0.761 \pm 0.020 \\
\mathrm{cA}\end{array}$ & $\begin{array}{l}0.387 \pm \\
0.016 \mathrm{cD}\end{array}$ & $\begin{array}{l}0.786 \pm 0.018 \\
\mathrm{cA}\end{array}$ & $\begin{array}{l}0.389 \pm \\
0.012 \mathrm{cD}\end{array}$ & $60 \mathrm{~min}$ & $\begin{array}{l}0.800 \pm 0.003 \\
\mathrm{bA}\end{array}$ & $\begin{array}{l}0.619 \pm \\
0.028 \mathrm{bB}\end{array}$ & $2 \mathrm{~h}$ & $\begin{array}{l}0.617 \pm 0.047 \\
\mathrm{cB}\end{array}$ & $\begin{array}{l}0.467 \pm \\
0.041 \mathrm{cC}\end{array}$ \\
\hline $3 d$ & $\begin{array}{l}0.685 \pm 0.022 \\
\mathrm{dA}\end{array}$ & $\begin{array}{l}0.321 \pm \\
0.023 \mathrm{dCD}\end{array}$ & $\begin{array}{l}0.691 \pm 0.020 \\
\mathrm{dA}\end{array}$ & $\begin{array}{l}0.298 \pm \\
0.014 \mathrm{dD}\end{array}$ & $90 \mathrm{~min}$ & $\begin{array}{l}0.700 \pm 0.012 \\
\mathrm{cA}\end{array}$ & $\begin{array}{l}0.519 \pm \\
0.032 \mathrm{cB}\end{array}$ & $3 \mathrm{~h}$ & $\begin{array}{l}0.498 \pm 0.014 \\
\mathrm{~dB}\end{array}$ & $\begin{array}{l}0.351 \pm \\
0.034 \mathrm{dC}\end{array}$ \\
\hline $4 d$ & $\begin{array}{l}0.589 \pm 0.017 \\
\mathrm{eA}\end{array}$ & $\begin{array}{l}0.243 \pm \\
0.011 \mathrm{eC}\end{array}$ & $\begin{array}{l}0.594 \pm 0.024 \\
\mathrm{eA}\end{array}$ & $\begin{array}{l}0.233 \pm \\
0.013 \mathrm{eC}\end{array}$ & $120 \mathrm{~min}$ & $\begin{array}{l}0.546 \pm 0.067 \\
d A\end{array}$ & $\begin{array}{l}0.418 \pm \\
0.005 \mathrm{cB}\end{array}$ & $4 \mathrm{~h}$ & $\begin{array}{l}0.432 \pm 0.019 \\
\mathrm{eB}\end{array}$ & $\begin{array}{l}0.249 \pm \\
0.035 \mathrm{eC}\end{array}$ \\
\hline $5 d$ & $\begin{array}{l}0.495 \pm 0.008 \\
\mathrm{fA}\end{array}$ & $\begin{array}{l}0.195 \pm \\
0.009 \mathrm{fE}\end{array}$ & $\begin{array}{l}0.504 \pm 0.009 \\
\text { fA }\end{array}$ & $\begin{array}{l}0.188 \pm \\
0.007 \mathrm{fE}\end{array}$ & $150 \mathrm{~min}$ & $\begin{array}{l}0.410 \pm 0.012 \\
\mathrm{eB}\end{array}$ & $\begin{array}{l}0.299 \pm \\
0.020 \mathrm{eD}\end{array}$ & $5 \mathrm{~h}$ & $\begin{array}{l}0.336 \pm 0.034 \\
\text { fC }\end{array}$ & $\begin{array}{l}0.205 \pm \\
0.008 \text { efE }\end{array}$ \\
\hline $6 \mathrm{~d}$ & $\begin{array}{l}0.398 \pm 0.020 \\
\text { gA }\end{array}$ & $\begin{array}{l}0.167 \pm \\
0.013 \mathrm{fDE}\end{array}$ & $\begin{array}{l}0.388 \pm 0.013 \\
\mathrm{gAB}\end{array}$ & $\begin{array}{l}0.101 \pm \\
0.020 \mathrm{gE}\end{array}$ & $180 \mathrm{~min}$ & $\begin{array}{l}0.3197 \pm \\
0.007 \mathrm{fBC}\end{array}$ & $\begin{array}{l}0.320 \pm \\
0.092 \mathrm{eC}\end{array}$ & $6 \mathrm{~h}$ & $\begin{array}{l}0.208 \pm 0.006 \\
g D\end{array}$ & $\begin{array}{l}0.183 \pm \\
0.006 \mathrm{fD}\end{array}$ \\
\hline
\end{tabular}

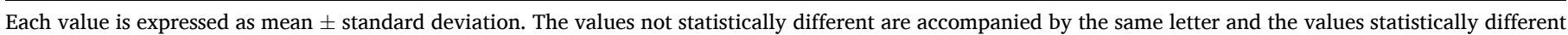
with another letter as compared to control (Small letter represent intra-group, capital letter represent inter-group).

compared to the first two treatments, temperature and oxygen has stronger effects on the thermal stability of the two samples (in an air dry oven at $50{ }^{\circ} \mathrm{C}$ ), and the loss of retention rate $(75.93 \%)$ was the most highest from 0 to $6 \mathrm{~h}$.

When the samples were exposed to ultraviolet light, the retention rate exhibited a variation trend similar to those of the self-assembled nanoparticles and free $\alpha$-TOC, and the retention rate decreased from $5.13 \%$ to $62.95 \%$ and from $7.85 \%$ to $61.37 \%$, respectively. The retention rate of the self-assembled nanoparticles was significantly higher $(\mathrm{p}<$ 0.05 ) than that of the free $\alpha$-TOC, which was ascribed to the fact that self-assembled nanoparticles can protect $\alpha$-TOC from the degradation caused by ultraviolet light, oxygen, temperature. Lang et al. [45] observed similar results for casein, that is, the increasing stability of blueberry anthocyanins due to $\alpha$-casein or $\beta$-casein was outstanding under thermal and photo conditions. $\alpha$-Tocopherol decomposes easily through oxidation when exposed to mitigating conditions, such as high temperature, oxygen, and light [28]. Previous studies indicate that the stability of the $\alpha$-tocopherol released from cold-set $\beta$-LG emulsion gels is considerably superior to that of free compounds [20].

\subsection{Antioxidant activity testing}

The effect of $\alpha$-TOC/CN nanoparticles and free $\alpha$-TOC on the formation of both LOOH and TBARS is shown in Fig. 6.

Both concentrations of $\alpha$-TOC/CN nanoparticles were able to inhibit lipid oxidation in the oil-in-water emulsion, as determined by both $\mathrm{LOOH}$ and TBARS assays. With the passage of time, the concentrations of $\mathrm{LOOH}$, the primary products of oil oxidation in the emulsion, first increased and then decreased. When the free $\alpha$-TOC concentration was $100 \mathrm{mg} / \mathrm{kg}$, the primary oxidation rate of oil was the highest, and the $\mathrm{LOOH}$ concentrations in the emulsion gradually increased to their maximum values with extension of the treatment time beyond $60 \mathrm{~min}$. $\mathrm{LOOH}$ concentrations remained at a low level throughout the course of the study in emulsions containing $200 \mathrm{mg} \alpha-\mathrm{TOC} / \mathrm{kg}$ oil with the nanoparticles. The presence of 100 and $200 \mathrm{mg} \alpha-\mathrm{TOC} / \mathrm{kg}$ oil led to a 78.54 and $63.54 \mu \mathrm{mol} / \mathrm{L}$ inhibition of TBARS formation with the nanoparticles, respectively, vs the free samples containing control after 180 mins. The increases in TBARS values were the greatest for the control samples with free $\alpha$-TOC, followed by the nanoparticles with a
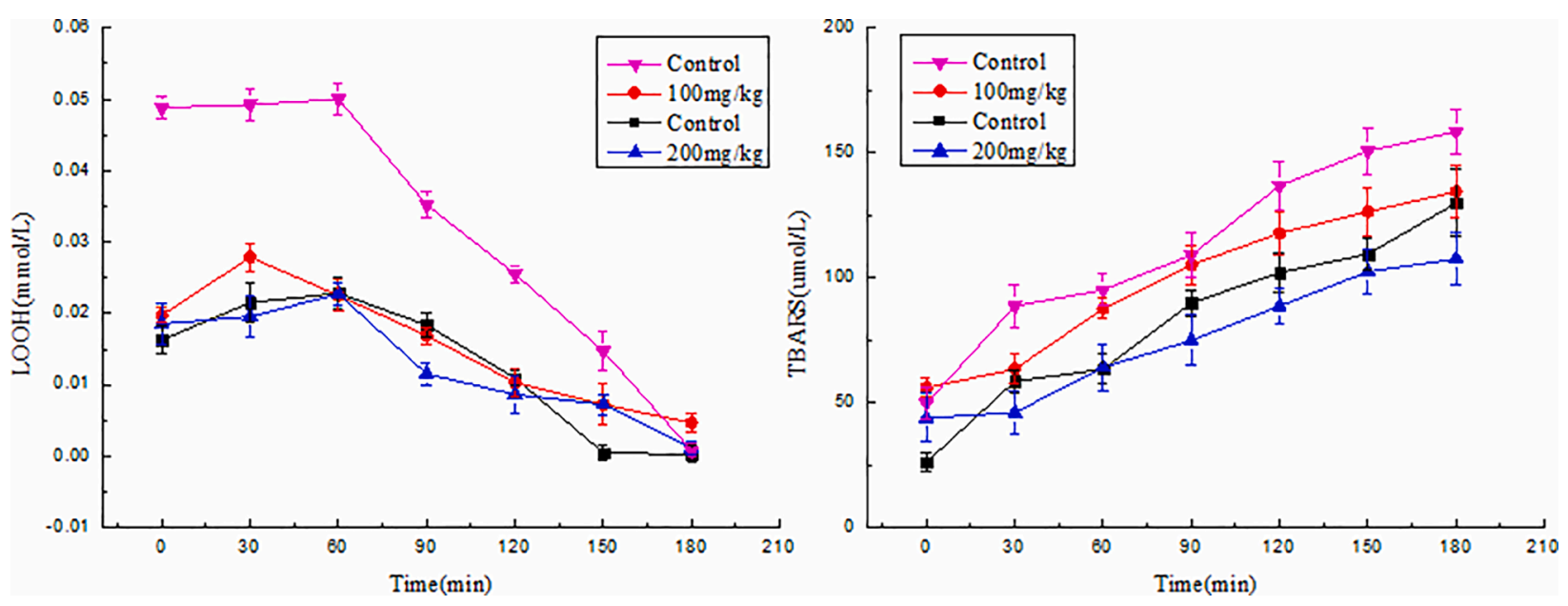

Fig. 6. Evolution of LOOH and TBARS in the four types of stabilized emulsions upon accelerated storage up to 180 min. 
concentration of $100 \mathrm{mg} / \mathrm{kg}$. Treatment with $200 \mathrm{mg} / \mathrm{kg}$ of nanoparticles led to smaller increases in the TBARS values of grape seed oil emulsion systems compared to those of the control samples. The reaction time could have promoted the decomposition of lipid hydroperoxides such that they did not accumulate but were instead converted to secondary lipid oxidation products, which were observed as high TBARS values. From these results shown, we can conclude that during accelerated oxidation treatment, more rapid molecular degradation of the free $\alpha$-TOC samples occurred due to temperature and air, leading to the formation of oxidation radicals in oil. Lipid oxidation is one the major causes of food spoilage, and fats and oils in processed foods are typically used in emulsion form [38]. Therefore, one strategy to inhibit lipid oxidation in oil-in-water emulsions is to use food additives that can bind and trap free radicals. Similar findings were reported for other oil emulsions, for example, at the oil-water interface, resveratrol can protect the oil by simply reacting with oxidizing agents [12]. Esmaili et al. [23] observed similar results for curcumin, in that the antioxidant activity of curcumin encapsulated in Beta-CN was higher than those of the two free samples.

\section{Conclusions}

Changes in UV-Vis spectra were recorded with two maxima at wavelengths of $195.5-212 \mathrm{~nm}$ and $275.5-285.5 \mathrm{~nm}$. The results of UV-Vis fluorescence spectrometry indicated that the secondary structure of casein changed in the presence of $\alpha$-TOC. The results of proton spectra indicated that the nanoparticles exhibited the chemical shifts of conjugated double bonds. The fluorescence intensities of casein decreased gradually with increasing $\alpha$-TOC concentrations, and the intrinsic fluorescence of casein was quenched by $\alpha$-TOC in a static pattern. The size and PDI of the particles changed significantly with ultrasonic treatment ( $300 \mathrm{~W}, 5 \mathrm{~min}$ ). Fourier deconvolution analysis and Gaussian curve fitting provided detailed information of the protein structures observed under different levels of treatment power $(0,100$, $200,300 \mathrm{~W})$ and various treatment times $(0,5,10$, and $15 \mathrm{~min})$. The ratio of $\alpha$-helix to $\beta$-sheet secondary structures decreased from 0.62 to 0.246 , which indicated that the structure of casein became more flexible. Under typical processing and storage conditions (thermal, photo, $20 \pm 2{ }^{\circ} \mathrm{C}$ and $4 \pm 2{ }^{\circ} \mathrm{C}$ ), the stability of $\alpha$-TOC increased due to its interaction with casein. The effects of casein on the antioxidant ability of $\alpha$-TOC were investigated using LOOH and TBARS assays, and the results represent remarkable outcomes.

\section{CRediT authorship contribution statement}

Libin Sun: Methodology, Writing - original draft, Funding acquisition. Hong Wang: Investigation, Data curation, Project administration. Xiang Li: Visualization. Sheng Lan: Formal analysis. Junguo Wang: Methodology, Formal analysis, Resources. Dianyu Yu: Conceptualization, Writing - review \& editing, Funding acquisition.

\section{Declaration of Competing Interest}

The authors declare that they have no known competing financial interests or personal relationships that could have appeared to influence the work reported in this paper.

\section{Acknowledgements}

This work was supported by a grant from the National Natural Science Foundation of China (No: 32072259), Heilongjiang Provincial Science and Technology Department (No:2020ZX08B01), special research funds of Jilin Business And Technology College of China (No: K2020003, LSK2020010).

\section{References}

[1] A. Mohamed, M.P. Hojilla-Evangelista, S.C. Peterson, G. Biresaw, Barley protein isolate:thermal, functional, rheological, and surface properties, J. Am. Oil Chem. Soc. 84 (3) (2007) 281-288.

[2] A. Sahu, N. Kasoju, U. Bora, Fluorescence study of the curcumin-casein micelle complexation and its application as a drug nanocarrier to cancer cells, Biomacromolecules 9 (10) (2008) 2905-2912.

[3] A.O. Elzoghby, W.S. Abo, N.A. El-Fotoh, Elgindy, Casein-based formulations as promising controlled release drug delivery systems, J. Control. Release 153 (2011) 206-216.

[4] Ana Cristina Soria, Mar Villamiel, Effect of ultrasound on the technological properties and bioactivity of food: a review, Trends Food Sci. Technol. 21 (7) (2010) 323-331.

[5] Ashkan Madadlou, Mohammad Ebrahimzadeh Mousavi, Zahra Emam-djomeh, Mohammadreza Ehsani, David Sheehan, Sonodisruption of re-assembled casein micelles at different pH values, Ultrason. Sonochem. 16 (5) (2009) 644-648.

[6] Carolina Montanheiro Noronha, Andrea Ferreira Granada, Sabrina Matosde Carvalho, Renata Calegari Lino, O.B. Matheus Viniciusde, Pedro Luiz Maciel, ManiqueBarreto, Optimization of $\alpha$-tocopherol loaded nanocapsules by the nanoprecipitation method, Ind. Crops Products 50 (2013) 896-903.

[7] E. Semo, E. Kesselman, D. Danino, Y. Livney, Casein micelle as a natural nanocapsular vehicle for nutraceuticals, Food Hydrocolloids 21 (5-6) (2007) 936-942.

[8] Farnaz Ahmadzadeh Nobari Azar, Akram Pezeshki, Babak Ghanbarzadeh, Hamed Hamishehkar, Maryam Mohammadi, Saeid Hamdipour, Hesam Daliri. Pectinsodium caseinat hydrogel containing olive leaf extract-nano lipid carrier: Preparation, characterization and rheological properties, LWT-Food Sci. Technol. 1482021111757.

[9] Feng Sheng, Yuning Wang, Xingchen Zhao, Na Tian, Huali Hu, Pengxia Li, Separation and identification of anthocyanin extracted from mulberry fruit and the pigment binding properties toward human serum albumin, J. Agric. Food Chem. 62 (28) (2014) 6813-6819.

[10] Greta Kresic, Vesna Lelas, Anet Režek Jambrak, Zoran Herceg, Suzana Rimac Brnčić, Influence of novel food processing technologies on the rheological and thermophysical properties of whey proteins, J. Food Eng. 87 (1) (2008) 64-73.

[11] Hao Hu, Jiahui Wu, Eunice C.Y. Li-Chan, Le Zhu, Fang Zhang, Xiaoyun Xu, Gang Fan, Lufeng Wang, Xingjian Huang, Siyi Pan, Effects of ultrasound on structural and physical properties of soy protein isolate (SPI) dispersions, Food Hydrocolloid 30 (2) (2013) 647-655.

[12] Haixia Zhang, Qi Fan, Di Li, Xing Chen, Li Liang, Impact of gum Arabic on the partition and stability of resveratrol in sunflower oil emulsions stabilized by whey protein isolate, Colloids Surf. B: Biointerfaces 181 (2019) 749-755.

[13] Imola Gabriela Zigoneanu, Carlos Ernesto Astete, Cristina Mirela Sabliov, Nanoparticles with entrapped a-tocopherol: synthesis, characterization, and controlled release, Nanotechnology 19 (2008), 105606.

[14] Jagannath Kuchlyan, Niloy Kundu, Debasis Banik, Arpita Roy, Nilmoni Sarkar, J. Kuchlyan, N. Kundu, D. Banik, et al., Spectroscopy and Fluorescence Lifetime Imaging Microscopy To Probe the Interaction of Bovine Serum Albumin with Graphene Oxide, Langmuir ACS J. Surf. Colloids 31 (2015) 13793-13801.

[15] Jianghong Tang, Feng Luan, Xingguo Chen, Binding analysis of glycyrrhetinic acid to human serum albumin: Fluorescence spectroscopy, FTIR, and molecular modeling, Bioorg. Med. Chem. 14 (9) (2006) 3210-3217.

[16] Jianmei Yu, Mohamed Ahmedna, Ipek Goktepe, Peanut protein concentrate: production and functional properties as affected by processing, Food Chem. 103 (1) (2007) 121-129.

[17] Jing-li Feng, Feng Jia, Jin-shui Wang, Yun-fang Gao, Xiao-pei Zhou, Xiao-wei Li, Effect of ultrasonic on the structural properties of casein, China Dairy Ind. 43 (2015) 20-23 (in Chinese with English abstract).

[18] Kim Rahmelow, Wigand Hübner.Secondary structure determination of proteins in aqueous solution by infrared spectroscopy: a comparison of multivariate data analysis methods, 2411996 5-13.

[19] Ladan Basiri, Ghadir Rajabzadeh, Aram Bostan, $\alpha$-Tocopherol-loaded niosome prepared by heating method and its release behavior, Food Chem. 221 (2017) 620-628.

[20] Li Liang, Valerie Leung, S. Line, G.E. Remondetto, M. Subirade. In vitro release of alpha tocopherol from emulsion-loaded b-lactoglobulin gels, Int. Dairy J. 202010 176-181.

[21] Li Liang, Vanessa Tremblay-Hebert, Muriel Subirade, Characterisation of the blactoglobulin/a-tocopherol complex and its impact on a-tocopherol stability, Food Chem. 126 (2011) 821-826.

[22] Lin Tang, Dong Zhang, Shanhua Xu, Huijun Zuo, Chunlin Zuo, Yufei Li, Different spectroscopic and molecular modeling studies on the interaction between cyanidin3-O-glucoside and bovine serum albumin, Luminescence 29 (2) (2014) $168-175$.

[23] Mansoore Esmaili, S. Mahmood Ghaffari, Zeinab Moosavi-Movahedi, Malihe Sadat Atri, Ahmad Sharifizadeh, Mohammad Farhadi, Reza Yousefi, JeanMarc Chobert, Thomas Haertlé, Ali Akbar Moosavi-Movahedi, Beta casein-micelle as a nano vehicle for solubility enhancement of curcumin;food industry application, LWT-Food Sci. Technol. 44 (10) (2011) 2166-2172.

[24] Marina Marsanasco, Andrés L. Márquez, Jorge R. Wagner, V. Silvia del, Nadia S. Alonso, Chiaramoni, Liposomes as vehicles for vitamins $\mathrm{E}$ and $\mathrm{C}$ : an alternative to fortify orange juice and offer vitamin $\mathrm{C}$ protection after heat treatment, Food Res. Int. 44 (2011) 3039-3046.

[25] Marta Corzo-Martínez, Antonia Montilla, Roberto Megías-Pérez, Agustín Olano, F. Javier Moreno, Mar Villamiel, Impact of high-intensity ultrasound on the 
formation of lactulose and Maillard reaction glycoconjugates, Food Chem. 157 (2014) 186-192.

[26] Michael Betz, Ulrich Kulozik, Whey protein gels for the entrapment of bioactive anthocyanins from bilberry extract, Int. Dairy J. 21 (9) (2011) 703-710.

[27] Mingmao Chen, Yan Liu, Huan Cao, Ling Song, Qiqing Zhang, The secondary and aggregation structural changes of BSA induced by trivalent chromium: a biophysical study, J. Luminescence 158 (2015) 116-124.

[28] Esther Miquel, Amparo Alegría, Reyes Barberá, Rosaura Farré, Gonzalo Clemente, Stability of tocopherols in adapted milk-based infant formulas during storage, Int. Dairy J. 14 (11) (2004) 1003-1011.

[29] Mohammad Ali Sahari, Hamid Reza Moghimi, Zahra Hadian, Mohsen Barzegar, Abdorreza Mohammadi. Physicochemical properties and antioxidant activity of atocopherol loaded nanoliposome's containing DHA and EPA, Food Chem. 2152017 157-164.

[30] Mohamed Eid, Remah Sobhy, Peiyuan Zhou, Xianling Wei, Di Wu, Bin Li. $\beta$-cyclodextrin-soy soluble polysaccharide based core-shell bionanocomposites hydrogel for vitamin E swelling controlled delivery, Food Hydrocolloids 1042020 105751.

[31] Pamela Torres, Adinarayana Kunamneni, Antonio Ballesteros, Francisco J. Plou, Enzymatic modification for ascorbic acid and alpha-tocopherol to enhance their stability in food and nutritional applications, Open Food Sci. J. 2 (1) (2008) 1-9.

[32] P. Bourassa, C.N. N'soukpoé-Kossi, H.A. Tajmir-Riahi, Binding of vitamin A with milk alpha- and beta-caseins, Food Chem. 138 (2013) 444-453.

[33] Phansiri Boonnoy, Mikko Karttunen, Jirasak Wong-ekkabut, Alpha-tocopherol inhibits poreformation in oxidized bilayers, Phys. Chem. Chem. Phys. 19 (8) (2017) 5699-5704.

[34] Qina Xia, Effects of Ultrasonic Pretreatment Combined with Maillard Reaction on Antioxidant Activity of Casein and Its Enzymatic Hydrolysates, Northeast Agricultural University, Harbin, 2019 (in Chinese with English abstract).

[35] Qiu-Ting Zhang, Zong-Cai Tu, Hui Xiao, Hui Wang, Xiao-Qin Huang, GuangXian Liu, Cheng-Mei Liu, Yan Shi, Liang-Liang Fan, De-Rong Lin, Influence of ultrasonic treatment on the structure and emulsifying properties of peanut protein isolate, Food Bioproducts Process. 92 (1) (2013) 30-37.

[36] Raju Onkar Sonawane, Savita Dattatraya Patil, Gelatin-к-carrageenan polyelectrolyte complex hydrogel compositions for the design and development of extended release pellets, Int. J. Polym. Mater. Polym. Biomater. 66 (16) (2017) 812-823.
[37] Richard E. Mcdonald, Herbert O. Hultin, Some characteristics of the enzymic lipid peroxidation system in the microsomal fraction of flounder skeletal muscle, J. Food Sci. 52 (1) (1987) 15-21.

[38] Ryan J. Elias, D. Julian McClements, Eric A. Decker, Antioxidant activity of cysteine, tryptophan, and methionine residues in continuous phase $\beta$-lactoglobulin in oil-in-water emulsions, J. Agric. Food Chem. 53 (26) (2005) 10248-10253.

[39] Sandra P. O' Dwyer, David O' Beirne, Deirdre Ní Eidhin, Brendan T. O' Kennedy, Effects of sodium caseinate concentration and storage conditions on the oxidative stability of oil-in-water emulsions, Food Chem. 138 (2-3) (2013) 1145-1152.

[40] Vladimir A Sirotkin, Albert N Zinatullin, Boris N Solomonov, Djihanguir A Faizullin, Vladimir D Fedotov, Calorimetric and Fourier transform infrared spectroscopic study of solid proteins immersed in low water organic solvents, Biochimica et Biophysica 1547 (2) (2001) 359-369.

[41] Sang-Ho Yoo, Young-Bin Song, Pahn-Shick Chang, Hyeon Gyu Lee, Microencapsulation of alphatocopherol using sodium alginate and its controlled release properties, Int. J. Biol. Macromol. 38 (2006) 25-30.

[42] Stelios D. Sarantis, Necla Mine Eren, Barbara Kowalcyk, Rafael Jiménez-Flores, Thermodynamic interactions of micellar casein and oat $\beta$-glucan in a model food system, Food Hydrocolloids 115 (2020), 106559.

[43] Yoav D. Livney, Milk proteins as vehicles for bioactives, Curr. Opin. Colloid Interface Sci. 15 (1-2) (2010) 73-83.

[44] Yun Shao, Chuan-He Tang, Characteristics and oxidative stability of soy proteinstabilized oil-in-water emulsions: Influence of ionic strength and heat pretreatment, Food Hydrocolloids 37 (2014) 149-158.

[45] Yuxi Lang, Haiyan Gao, Jinlong Tian, Chi Shu, Renyan Sun, Bin Li, Xianjun Meng, Protective effects of $\alpha$-casein or $\beta$-casein on the stability and antioxidant capacity of blueberry anthocyanins and their interaction mechanism, LWT-Food Sci. Technol. 115 (2019) 108434, https://doi.org/10.1016/j.lwt.2019.108434.

[46] Zhen Wang, Junhui Chen, Shaobin Wang, Zhanguang Chen, Characterizing the interaction between oridonin and bovine serum albumin by a hybrid spectroscopic approach, J. Luminescence 134 (2013) 863-869.

[47] Zhiyong He, Jie Chen, Sydney E. Moser, Owen G. Jones, Mario G. Ferruzzi, Interaction of $\beta$-casein with (-)-epigallocatechin-3-gallate assayed by fluorescence quenching: Effect of thermal processing temperature, Int. J. Food Sci. Technol. 51 (2) (2016) 342-348.

[48] Bingcan Chen, David Julian McClements, Eric Andrew Decker, Role of Continuous Phase Anionic Polysaccharides on the Oxidative Stability of Menhaden Oil-inWater Emulsions. J. Agr. Food Chem. 58 (2010) 3779-3784. 